\title{
The Convective System Area Expansion over Amazonia and Its Relationships with Convective System Life Duration and High-Level Wind Divergence
}

\author{
Luiz Augusto T. Machado* and Henri Laurent ${ }^{+}$ \\ Divisão de Ciências Atmosféricas, Centro Técnico Aeroespacial, Instituto de Aeronáutica e Espaço São José dos Campos,
} São Paulo, Brazil

(Manuscript received 4 November 2002, in final form 2 September 2003)

\begin{abstract}
The relationships between the initial area expansion rate of tropical convective systems and their total life duration are analyzed during the period of the Wet Season Amazon Mesoscale Campaign/Large-Scale BiosphereAtmosphere (WETAMC/LBA) experiment over tropical South America, using an objective tracking of convective systems during their life cycle from infrared Geostationary Operational Environmental Satellite (GOES) images. The results show that it is possible to estimate the probable lifetime of a convective system, within certain error bars, considering only its initial area expansion. This result shows that the initial area expansion could be used as a predictor of the life cycle of convective systems. The area expansion is also a good indicator of convective activity such as the diurnal cycle of convection. Over the southwest Amazon, the maximum area expansion occurs close to the time of maximum precipitation and about $4 \mathrm{~h}$ before the maximum cold cloud fraction at the same threshold $(235 \mathrm{~K})$.

Also, the hypothesis that the area expansion, and hence the convective activity, impacts the high-level wind divergence has been investigated using satellite wind observations. It is found that the wind divergence fields derived are able to describe the large-scale patterns but are not able to capture the small-scale features. The diurnal cycle of the high-level wind divergence generally shows a flat response over tropical South America, although a coherent but not significant signal is observed over the WETAMC/LBA area. It is shown that the area of the cloud shield of convective systems varies not only in association with the upper-level wind divergence but also with the condensation-evaporation process. The increase of area in this initial stage is mainly due to the condensation process. During the ensuing mature stage, the upper-air wind divergence also contributes to the expansion.
\end{abstract}

\section{Introduction}

Convective systems are responsible for most of the rainfall in tropical regions as well as in temperate latitudes during the warm season, and they are also responsible for some extreme weather conditions in various regions of the earth. Knowledge of convective system evolution is of fundamental importance for understanding weather and climate, particularly in the Tropics, and it is essential for improving forecasting of these systems to reduce vulnerability to extreme weather damage. The identification of predictor parameters for the evolution of a convective system, based on its previous evolution, could make a significative contribution to a nowcasting scheme and provide important information for mesoscale model initialization.

\footnotetext{
* Current affiliation: CPTEC/INPE, Cachoeira-Paulista, São Paulo, Brazil.

${ }^{+}$Current affiliation: LTHE, IRD, Grenoble, France.
}

Corresponding author address: Dr. Henri Laurent, LTHE/IRD, BP 53, 38041 Grenoble Cedex 9, France.

E-mail: Henri.Laurent@ird.fr
Machado et al. (1998), using a methodology able to track convective systems during their life cycle, suggested that the surface expansion of a convective system could be associated with the high-level wind divergence and the length of the life cycle. They showed that large initial growth rates characterize large and long-lived convective systems and suggest a large updraft inside the convective towers consistent with high cloud tops and large upper-level divergence. Knowledge of the divergence field is important for understanding the tropical atmospheric circulation. Cumulus-scale convection supplies the energy needed to force large-scale disturbances that will in turn produce the low-level moisture convergence needed to drive the convection, resulting in ascending motions in the convective systems and divergence at high levels due to mass continuity (Holton 1979). Unfortunately, conventional observations are very few in tropical and oceanic regions; therefore, satellite data must be used to study convective atmospheric circulations. Wind vectors estimated from successive water vapor channel satellite images are numerous, provide consistent wind fields at high levels (Laurent 1993; Velden et al. 1997), and can be used for climatological 


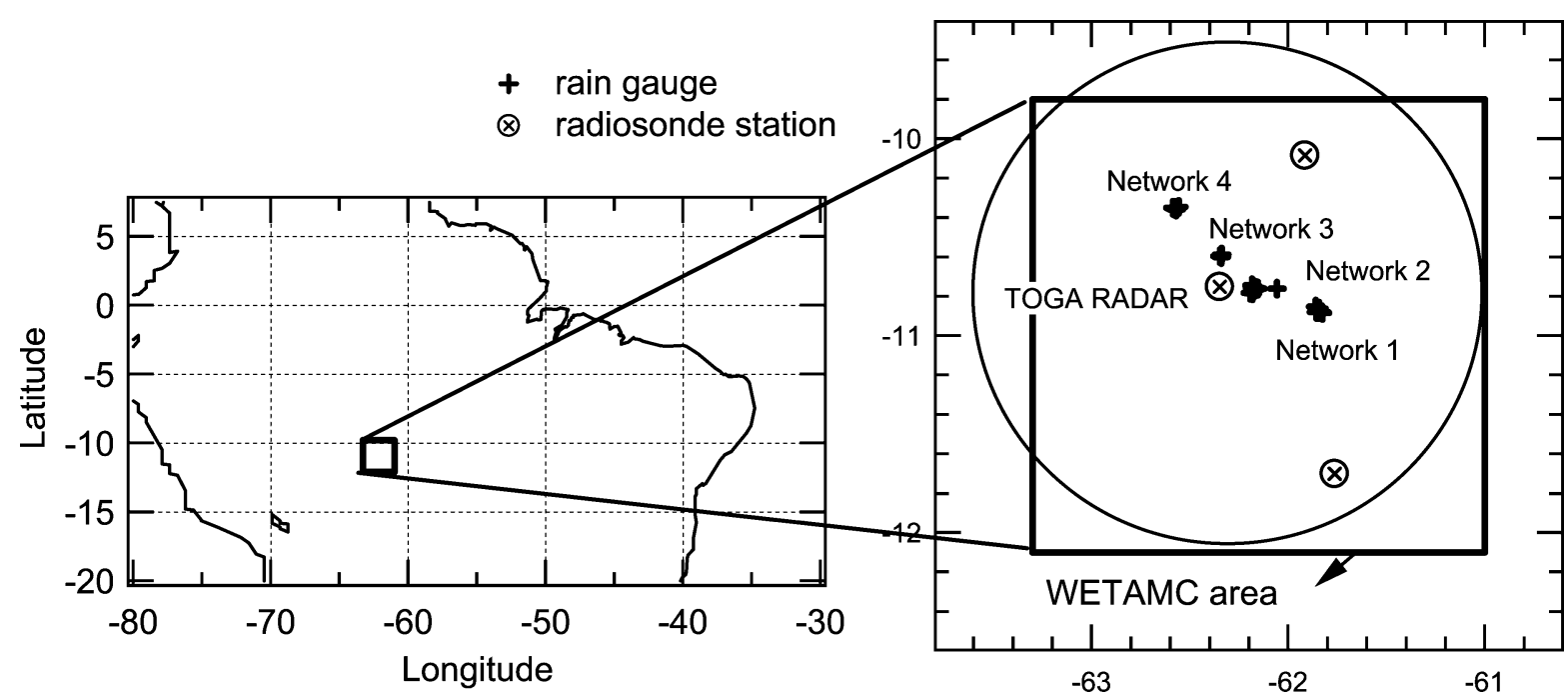

FIG. 1. (left) Region used to track the convective systems from GOES images and the location of the WETAMC/LBA area. (right) Location of the 150-km range of the TOGA radar (circle), the WETAMC area (square), the rain gauges clustered in four networks, and the radiosounding stations.

studies (Schmetz et al. 1995) or to monitor convective systems. Laurent and Sakamoto (1998) calculated the high-level wind divergence from water vapor wind fields. They showed that the areas with low brightness temperature, corresponding to convective systems, are well correlated with large divergence values.

Scofield (1987) presented a technique to estimate precipitation using image satellite based on the time evolution of the convective cloud area. Estimates of convective rainfall are computed by comparing the changes in cloud characteristics that are observed between two consecutive images of enhanced infrared and visible images. This technique and others of similar nature have shown that the area evolution of a convective system can be associated with the intensity of the precipitation.

This study utilizes the dataset collected during the Wet Season Amazon Mesoscale Campaign (WETAMC) held in January-February 1999, in the Rondônia state in Brazil, as part of the Large-Scale Biosphere Atmosphere (LBA) experiment (Silva Dias et al. 2002). Several instruments for measuring precipitation as part of the ground validation of the Tropical Rainfall Measuring Mission (TRMM) satellite were also included in WETAMC (Petersen et al. 2002). The TRMM-WETAMC/ LBA experiment presents a unique opportunity to analyze the convective processes in the Amazon, enabling study of convective systems by combining different measurements such as satellite, radar, radiosonde, and rain gauge.

The growth rate of the convective systems can be deduced from their area expansion, which is easily observed from successive satellite images. This area expansion is expected to be associated with the high-level wind divergence and with the rate of condensation/evaporation that is directly related to the mass flux inside the convective system. The objective of this study is to investigate these hypotheses to examine if the rate of change of area of a convective system can be associated with its lifetime and if this rate can indicate the level of convective activity.

In section 2 the in situ and satellite data used in this study are presented. Section 3 presents the initial area expansion of the convective systems and its relationship with the system duration. The diurnal cycle of the area expansion is shown in section 4 and compared with precipitation and high-level wind divergence in the WETAMC region. The relationships between area expansion and high-level wind divergence are analyzed in section 5. Section 6 summarizes the main conclusions.

\section{Data}

\section{a. Rain gauge, radar, and radiosonde data}

The WETAMC/LBA allows us to study the threedimensional structure of convective systems and their associated precipitation using a combination of meteorological radars, rain gauge network, TRMM active and passive sensors, and radiosonde data. Figure 1 shows the location of the experiment and the many instruments used in this study.

The rain gauge network was distributed in four clusters. The rain gauge tipping buckets have a sampling resolution of $0.254 \mathrm{~mm}$ and maximum temporal resolution of $10 \mathrm{~s}$. In this study we used the hourly accumulated rain gauge data from the Goddard Distributed Active Archive Center (DAAC). An average over the four networks was applied to describe the average hourly rainfall over the TRMM-WETAMC region (see Fig. 1 for location).

Three radiosonde stations performed 3-hourly soundings during the experiment: Rebio Jaru (RJ: $10^{\circ}, 5^{\prime} \mathrm{S}$, 
$61^{\circ}, 55^{\prime} \mathrm{W}$; altitude, $\left.120 \mathrm{~m}\right)$; Abracos (AB: $10^{\circ}, 45^{\prime} \mathrm{S}$, $62^{\circ}, 21^{\prime} \mathrm{W}$; altitude, $290 \mathrm{~m}$ ); Rolim de Moura (RM: $11^{\circ}$, $42^{\prime} \mathrm{S}, 61^{\circ}, 46^{\prime} \mathrm{W}$; altitude, $225 \mathrm{~m}$ ). These three stations form a triangle, allowing for the computation of horizontal wind divergence using the Kelvin and Green theorem. Machado (2000) used this method to compute the fields of mass and energy divergence in the Amazon region. In this study we will focus on the $200-\mathrm{hPa}$ wind divergence.

Data from the National Aeronautics and Space Administration (NASA) C-band radar (wavelength of 5.4 $\mathrm{cm}$ ) known as the Tropical Ocean and Global Atmosphere Program (TOGA) radar were used to track the displacements of the rain cell echoes. During the experiment, complete volume scans were performed at 10min intervals, from which was calculated the 2-km constant altitude plan position indicator (CAPPI), following Anagnostou and Krajewski (1997). We used CAPPIs with a horizontal resolution of $5 \mathrm{~km} \times 5 \mathrm{~km}$ limited to a range of $150 \mathrm{~km}$ to be consistent with the horizontal resolution obtained in the Geostationary Operational Environmental Satellite (GOES) IR images. The TOGA radar calibration was also adjusted using the TRMM precipitation radar (Anagnostou and Morales 2002). With the same methodology as described for the satellite data in section $2 b$, the rain cells observed in the CAPPI 2-km data were tracked throughout their life cycle, considering only the cells that initiated and dissipated spontaneously inside the $150-\mathrm{km}$ disk. The rain cells delimited with the $20-\mathrm{dBZ}$ threshold include weak to strong rainfall. More details on the methodology can be found in Laurent et al. (2002).

\section{b. Satellite data processing}

The GOES- 8 satellite images were preprocessed by NASA Goddard Space Flight Center (GSFC) for the entire duration of the experiment at full resolution (every $30 \mathrm{~min}$; pixel size of $\sim 4 \mathrm{~km}$ for the infrared channels). The convective systems are detected using the thermal infrared channel $(\sim 11 \mu \mathrm{m})$ assuming that the convective clouds that are high and thick are those with a small brightness temperature. A convective system is here defined as an area of at least 200 pixels (i.e., an area larger than about $3500 \mathrm{~km}^{2}$ ) that falls below the temperature threshold. Two thresholds were used: 235 $\mathrm{K}$ to identify the whole convective system including the thick cirrus shield and $210 \mathrm{~K}$ to identify the areas of very intense convection that may exist embedded in the convective system. The systems are tracked during their life cycle using the method described by Mathon and Laurent (2001) that determines whether the system initiates spontaneously or from a split, and whether it ends by dissipation or by merging into another system. This objective tracking was performed for the period 11 January-27 February over a window covering tropical South America approximately from $7.5^{\circ} \mathrm{N}$ to $20^{\circ} \mathrm{S}$ and from $80^{\circ}$ to $30^{\circ} \mathrm{W}$. The total number of systems tracked was 13409 at $235 \mathrm{~K}$ and 3867 at $210 \mathrm{~K}$. For comparison with the WETAMC/LBA observations, we use a window defined by $12^{\circ}-8^{\circ} \mathrm{S}$ and $64^{\circ}-60^{\circ} \mathrm{W}$ (see Fig. 1). A more detailed description of the methodology is given in Laurent et al. (2002).

According to the average radiosonde profile, the 235$\mathrm{K}(210 \mathrm{~K})$ level is located around $260 \mathrm{hPa}(160 \mathrm{hPa})$. Indeed, as the temperatures of the convective system pixels are lower than $235 \mathrm{~K}$, the system top level is somewhere above the $260 \mathrm{hPa}$ level. To estimate the wind divergence associated with the system top, we will therefore consider the slice from 250 to $150 \mathrm{hPa}$.

\section{Area expansion of the convective systems}

\section{a. Definition of the area expansion}

The convective system area is calculated from the number of pixels with a brightness temperature smaller than the given threshold (235 or $210 \mathrm{~K})$. The area expansion rate is simply the normalized difference of the system area between two successive images (Machado et al. 1998). The area expansion is closely linked to the phase of the convective system life. At the beginning of its life the convective system presents a large positive area expansion. The area expansion is close 0 during the mature phase of the system and negative during the dissipative phase. The magnitude of the area expansion may be a good indicator to monitor the convective activity of the convective system, acting as a proxy to quantify the mass flux or the condensation rate inside the convective system.

Machado et al. (1998) discuss the possibility of associating the area expansion of the convective systems with the high-level wind divergence, if condensation and evaporation are neglected, with the following equation:

$$
A_{e}=\frac{1}{A} \frac{\partial A}{\partial t} \approx \boldsymbol{\nabla} \cdot \mathbf{V}
$$

where $A$ is the convective system area, and $\mathbf{V}$ is the horizontal wind vector. In this paper, $A_{e}$ is the normalized area time rate of expansion called area expansion. A negative area expansion corresponds to contraction. Rapid area expansion would correspond to large upperlevel wind divergence (e.g., Wallace and Hobbs 1979).

Machado et al. (1998) suggest that the magnitude of the area expansion at the initial time may be related to the total duration of the convective system. They found that the area expansion is systematically larger at the initiation stage for long-lived convective systems. There are two possible reasons for this: (i) the environmental conditions that are needed for vigorous development of convection, such as low-level moisture convergence and vertical conditional instability, are likely to persist during the following hours; and (ii) a strong area expansion indicates a strong internal dynamic (strong mass flux) of the convective system that will transport energy to 


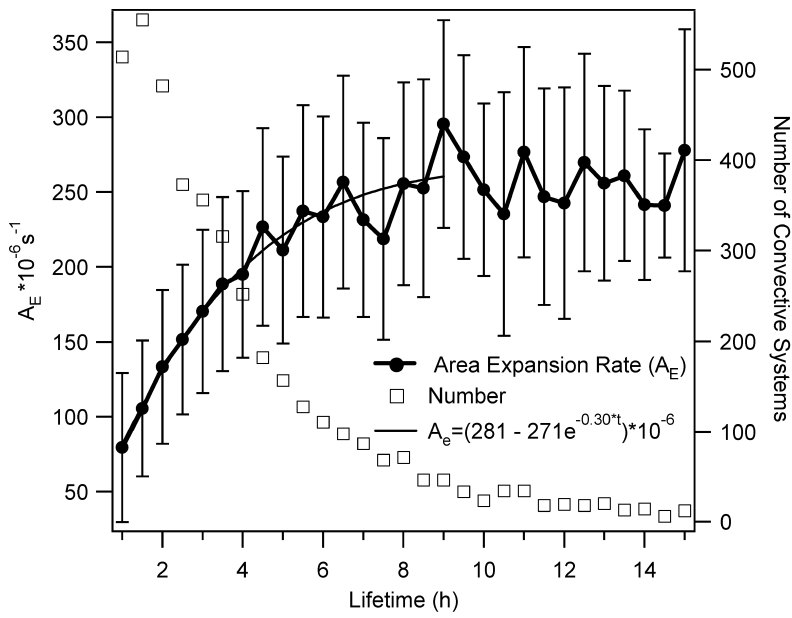

FIG. 2. Area expansion $\left(\mathrm{A}_{\mathrm{e}} ; 10^{-6} \mathrm{~s}^{-1}\right)$ and associated std dev as a function of the convective system lifetime (h). The number of cases is also plotted (right axis).

the middle to high troposphere, modifying the atmospheric circulation and favoring the low-level moisture convergence that will in turn prolong the life of the convective system. This feedback is likely to be activated if the convective system has a strong internal mass flux in the initial stage. Note that as the convective systems have a size larger than $3500 \mathrm{~km}^{2}$, they include various convective towers, and the satellite analysis is an integration of all small-scale features.

\section{b. Relationship between area expansion and lifetime}

The work of Machado et al. (1998) was based on a low-resolution dataset and did not consider the different situations of splitting and merging of convective systems. This study aims to test the hypotheses mentioned using high-resolution data from various sources. In order to analyze the relationship between the area expansion of a convective system and its lifetime, we only consider here the systems that initiate spontaneously (i.e., not as a result of a split of a former system) and end by dissipation (i.e., not by merging into another system). This ensures that the initial growth of the system is due to its internal dynamics and that the lifetime is representative of a complete life cycle. The tracking method allows for such a selection; the number of systems is thus reduced to 4240 at $235 \mathrm{~K}$ and 2569 at $210 \mathrm{~K}$.

The average relationship between area expansion at the initial time (between $\mathrm{t} 0$ and $\mathrm{t} 0+30 \mathrm{~min}$ ) and total lifetime is shown in Fig. 2. The plot gives the mean area expansion observed for each life duration and the associated standard deviation. The number of observed convective systems is also indicated. On average, the convective systems with a weak area expansion during the initial phase have a short lifetime. The convective system duration increases as its initial area expansion increases. The fitted curve shows that there is a nearly

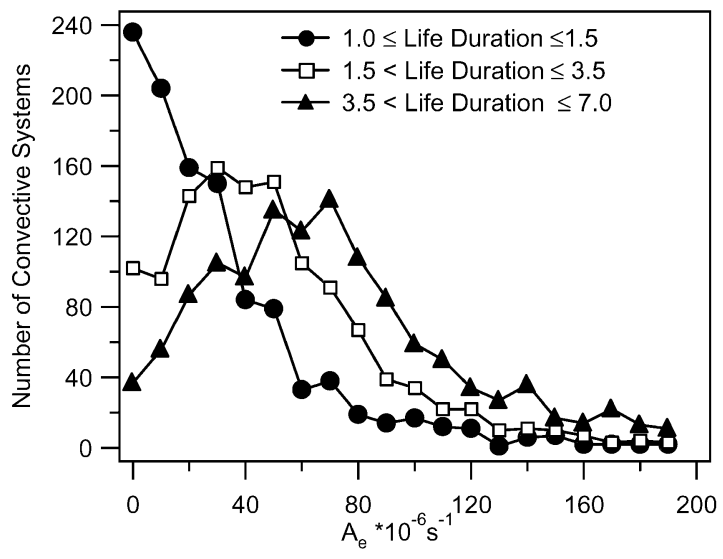

FIG. 3. Histogram of the area expansion $\left(10^{-6} \mathrm{~s}^{-1}\right)$ for three classes of convective system lifetime.

exponential relationship. For life duration larger than 8 $\mathrm{h}$ the function could be asymptotic; however, the small number of cases leads to a very noisy and inconclusive relationship. For most cases (lifetime smaller than $8 \mathrm{~h}$ ) the results show that the area expansion is a good indicator of the lifetime, within error bars, and that the relationship can be approximated by an exponential function.

The relationship shown in Fig. 2 is valid on average, but there is considerable variability. Figure 3 shows the histogram of the area expansion values for three classes of convective systems: lifetime of 1 and $1.5 \mathrm{~h}$, from 2 to $3.5 \mathrm{~h}$, and from 4 to $7 \mathrm{~h}$. Each class has approximately the same population. The three histograms are different, showing that there is a larger probability that a small area expansion is associated with a short lifetime than with a long one. However, it can also be seen that there is quite a large dispersion; in other words, a given area expansion value can be associated with different life durations. In fact it is not only the initial conditions but also other factors that can impact the growth and duration of convective systems, for instance, the topography, breeze effect, or any change of forcing during the life of the system. However, it is beyond the scope of this paper to reach a full understanding of these different cases.

To analyze the impact of the threshold used to define the convective systems and hence their area expansion and lifetime, the same calculations were performed for a threshold of $210 \mathrm{~K}$. Figure 4 shows the area expansion at the initial time versus lifetime for convective systems defined at 210 and $235 \mathrm{~K}$. There is a similar relationship for both cases. For the convective systems defined with the colder threshold, the coefficient of the exponential fitting is -0.5 instead of -0.3 . According to Eq. (1), this means that the high-level wind divergence associated with the convection is larger when the convective system has a very cold top, consistent with the idea that in a given location the higher the convective cloud top, the more intense the convective activity. On the one 


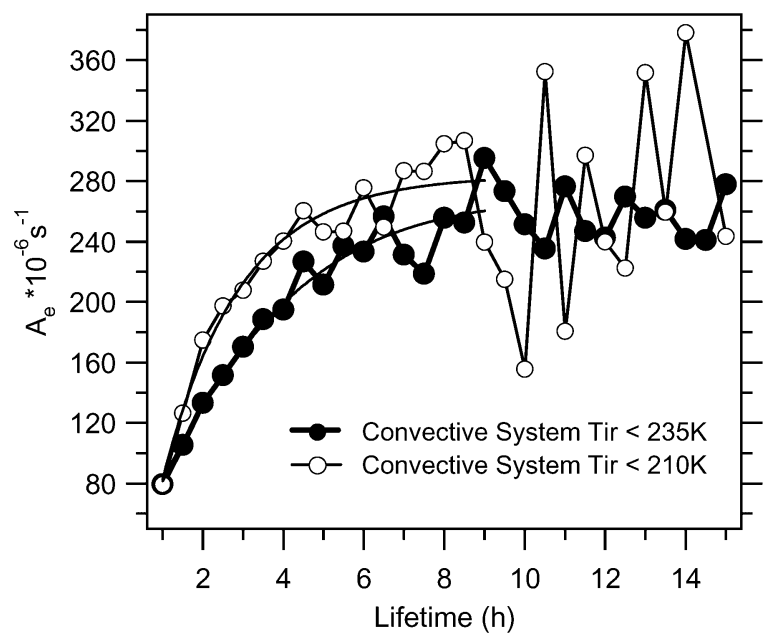

FIG. 4. Area expansion $\left(10^{-6} \mathrm{~s}^{-1}\right)$ vs lifetime (h) for the convective systems defined at 235 or $210 \mathrm{~K}$.

hand, the relationship between initial area expansion and lifetime seems sharper with the $210-\mathrm{K}$ threshold than with the $235-\mathrm{K}$ threshold. This is likely to be due to the shorter lifetime of the convective cells (convective systems defined by $210 \mathrm{~K}$ ) merged inside the convective system. On the other hand, the number of $210-\mathrm{K}$ convective cells is smaller, and the area expansion variability is very large for lifetimes larger than $5 \mathrm{~h}$. The initial time of the convective cells comes after the initial time of the convective system at a warmer threshold. Therefore, considering a possible application of the present study in nowcasting, it is preferable to focus on the earlier-detected, 235-K convective systems. Another parameter that needs to be analyzed is the time interval used to calculate the area expansion. In the previous results the minimum interval was used: $30 \mathrm{~min}$ between the first and the second image containing the convective system considered. However a larger time interval can be used. Figure 5 shows the area expansion versus lifetime relationship when computing the area expansion over an initial time interval of $30,60,90$, or $120 \mathrm{~min}$. The relationship remains very similar but the values of the area expansion vary by a factor of 1.7. Nevertheless, it should be noted that a shorter time interval is much more useful for nowcasting. Note that the wind divergence is also very dependent on the time interval over which it is computed. Based on these results, an empirical relationship between area expansion and life cycle duration can be established. This relationship will depend on the threshold and the time interval between two successive images.

The results indicate that a mean relationship exists between the area expansion at the initial time and the lifetime of the convective systems. This relationship depends on the definition of a convective system and the time interval considered. The main point is that it is possible to estimate the highest probability duration of a convective system, within certain error bars, consid-

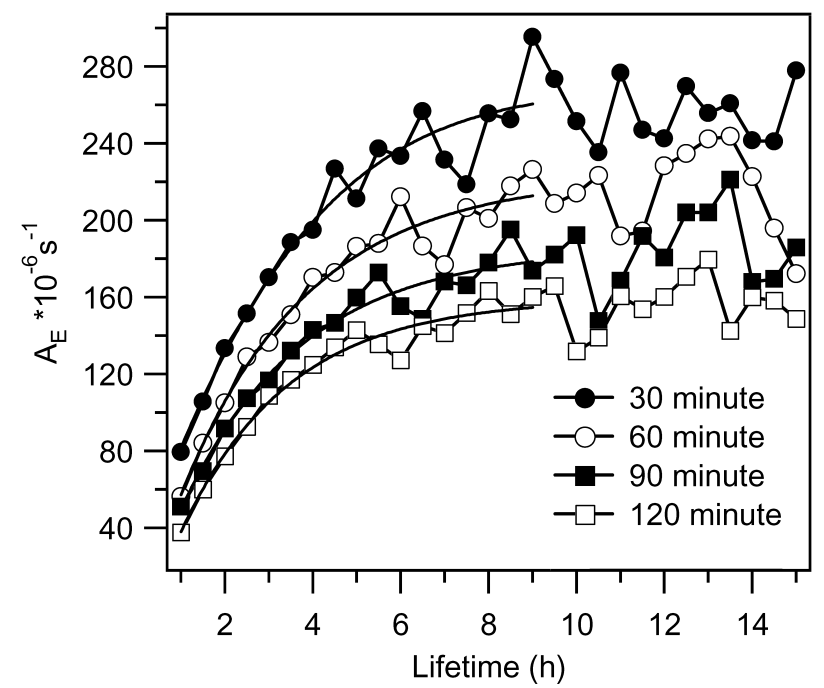

FIG. 5. Area expansion $\left(10^{-6} \mathrm{~s}^{-1}\right)$ vs lifetime (h) of the convective systems for area expansion calculated with a time interval of 30,60 , 90 , or $120 \mathrm{~min}$.

ering only its growth rate during its initiation phase. The same is true for the size of the convective system, as there is a good relationship between size and lifetime (Machado et al. 1998; Mathon and Laurent 2001). Figure 6 presents a simplified representation of the convective system life cycle. The faster the initial growth rate, the larger the size and the duration of the system.

Using the CAPPI $2-\mathrm{km}$ data from the TOGA radar, the area expansion can be computed in the same way as for the satellite data. The area expansion of the rain cells is closely linked to the water condensed at $2-\mathrm{km}$ height, resulting from low-level moisture convergence. Figure 7 shows the area expansion of the rain cell as a function of the rain cell duration. The number of cases is quite small because of the rejection of every case of splitting or merging and also because of the small area covered by the radar. It can be seen, however, that the

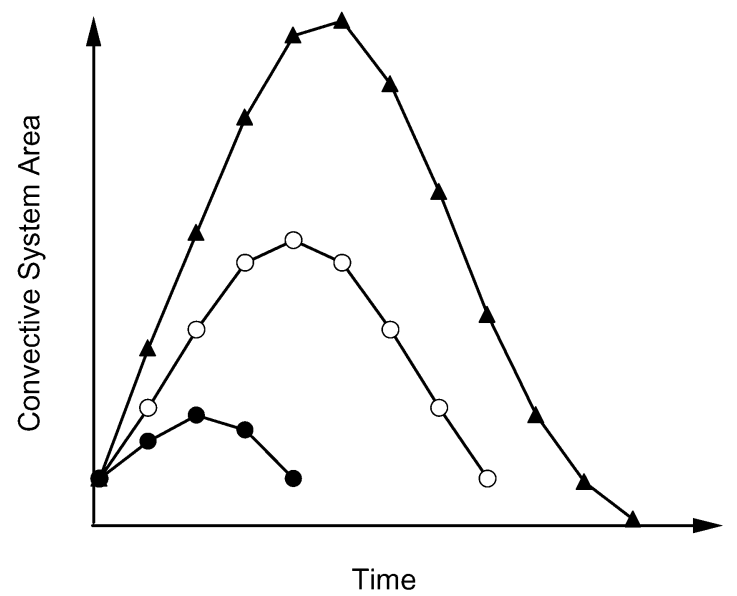

FIG. 6. Schematic diagram of the convective system size evolution for different initial area expansions. 


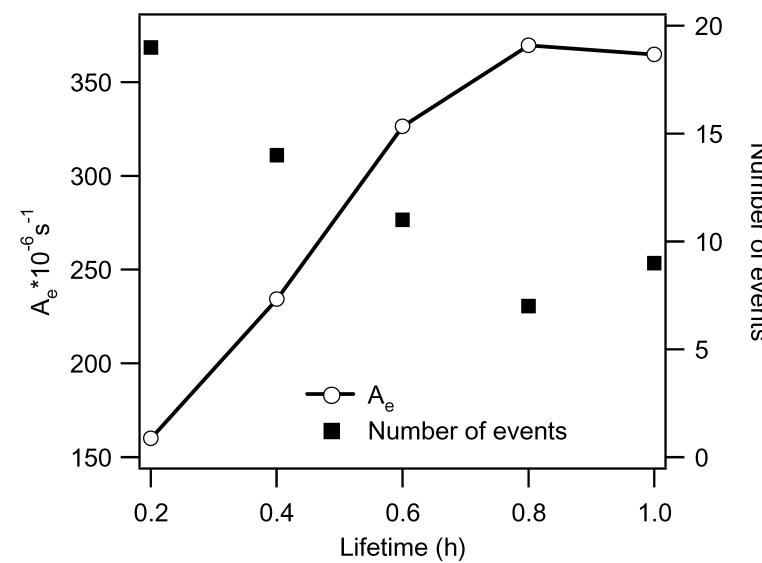

FIG. 7. Area expansion $\left(10^{-6} \mathrm{~s}^{-1}\right)$ vs rain cell lifetime (h), using CAPPI 2-km data with the $20-\mathrm{dBZ}$ threshold. The number of cases is also indicated (right axis).

relationship is similar to what is observed for the convective systems (Fig. 2). Note the difference in time scale between the rain cells (typically $1 \mathrm{~h}$ ) and the convective systems (typically $10 \mathrm{~h}$ ). In the latter case the rapid increase of area of liquid water in the initiation stage can be linked with the vigor of the dynamics associated with the convective system. The radar data observations suggest that the area expansion can be closely associated with the low-level humidity convergence, and the effect of the condensation probably cannot be neglected, as will be discussed in section 5 .

\section{The diurnal cycle of the area expansion, precipitation, and wind divergence}

One of the main difficulties in comparing the convective system area expansion with the high-level wind divergence arises from the different time and space scales involved. As was mentioned before, the wind divergence depends strongly on the space-time scale. In order to investigate how Eq. (1) can be used to relate the cloud shield expansion with the wind divergence, we need to make some simplifications:

- The area expansion is considered as uniform for the whole convective system area (threshold, $235 \mathrm{~K}$ ), which is reasonable when considering the mean behavior. Actually, as seen in Fig. 4 the coldest parts of the system are associated with larger values of area expansion and therefore divergence. We do not attempt to detail here the internal structure of the systems but rather try to understand their mean behavior.

- The pressure level corresponding to $235 \mathrm{~K}$ is about $250 \mathrm{hPa}$ in the region of the experiment; however, a large fraction of the cloud system top is at higher levels. We consider here a slice of $200 \mathrm{hPa} \pm 50 \mathrm{hPa}$ as representative of the whole convective system top.

The area expansion has been computed for every convective system for each 30-min interval. The values obtained over each system have then been interpolated on a regular $1^{\circ} \times 1^{\circ}$ grid using the Barnes (1964) methodology. The average 3-hourly fields computed over the period 10 January-29 February 1999 are presented in Fig. 8. This figure shows that the area expansion describes very clearly the diurnal cycle of the convection. The large convective activity develops over the Amazon region at about $1300 \mathrm{LST}$, that is, $1600 \mathrm{UTC}$ at $45^{\circ} \mathrm{W}$ and $1700 \mathrm{UTC}$ at $60^{\circ} \mathrm{W}$. During nighttime the convective systems dissipate (negative area expansion) in agreement with the diurnal cycle described by Machado et al. (2002).

To compare the area expansion with the high-level wind divergence, we have used high-level wind measurements obtained from successive water vapor (WV) channel GOES images (Velden at al. 1997). These socalled WV winds have been computed every $3 \mathrm{~h}$ for the entire WETAMC/LBA experiment by National Oceanic and Atmospheric Administration/National Environmental Satellite, Data, and Information Service (NOAA/ NESDIS). The wind vectors in the 150-250-hPa layer are here interpolated onto a $1^{\circ} \times 1^{\circ}$ grid using the same method as applied to the area expansion. The divergence is then calculated by finite differences. The mean divergence computed from the WV winds is presented in Fig. 9. The WV wind mainly describes the large-scale field. The divergence field in Fig. 9 is very close to the cold cloud occurrences for a brightness temperature threshold of $235 \mathrm{~K}$ (not shown). The $200-\mathrm{hPa}$ WV wind vectors are derived from the motions of high-level clouds, whereas the water vapor structure motions derived in regions free of high-level clouds are assigned to lower levels than $250 \mathrm{hPa}$. Therefore the regions of subsidence are not considered in the $200-\mathrm{hPa}$ field. The variability of divergence time series is large (standard deviation of almost $2 \times 10^{-5} \mathrm{~s}^{-1}$ ), which can explain that the mean diurnal variation of the $200-\mathrm{hPa}$ WV wind divergence over the whole region is quite noisy and does not show a clear diurnal cycle (not shown).

In order to compare the area expansion, the wind divergence from radiosonde and the WV wind divergence, we focus on the WETAMC/LBA area defined by the region from $12^{\circ}$ to $8^{\circ} \mathrm{S}$ and $64^{\circ}$ to $60^{\circ} \mathrm{W}$. To compute the area expansion and the water vapor wind, only the convective systems and the wind vectors inside these areas are considered. The divergence computed from radiosonde is obtained from the three radiosonde sites, and the methodology is described in section $2 \mathrm{a}$.

Figure 10 shows the average diurnal variation for the 200-hPa level of the wind divergence from radiosonde, the WV wind divergence, and the area expansion. There is a coherent phase variation among these parameters, exhibiting a maximum in the beginning of the afternoon close to the time of maximum precipitation (see Fig. 11). During nighttime, according to the radiosonde data, there is a secondary maximum, barely visible with the water vapor wind divergence and the area expansion. Machado et al. (2002) have shown that the convective 

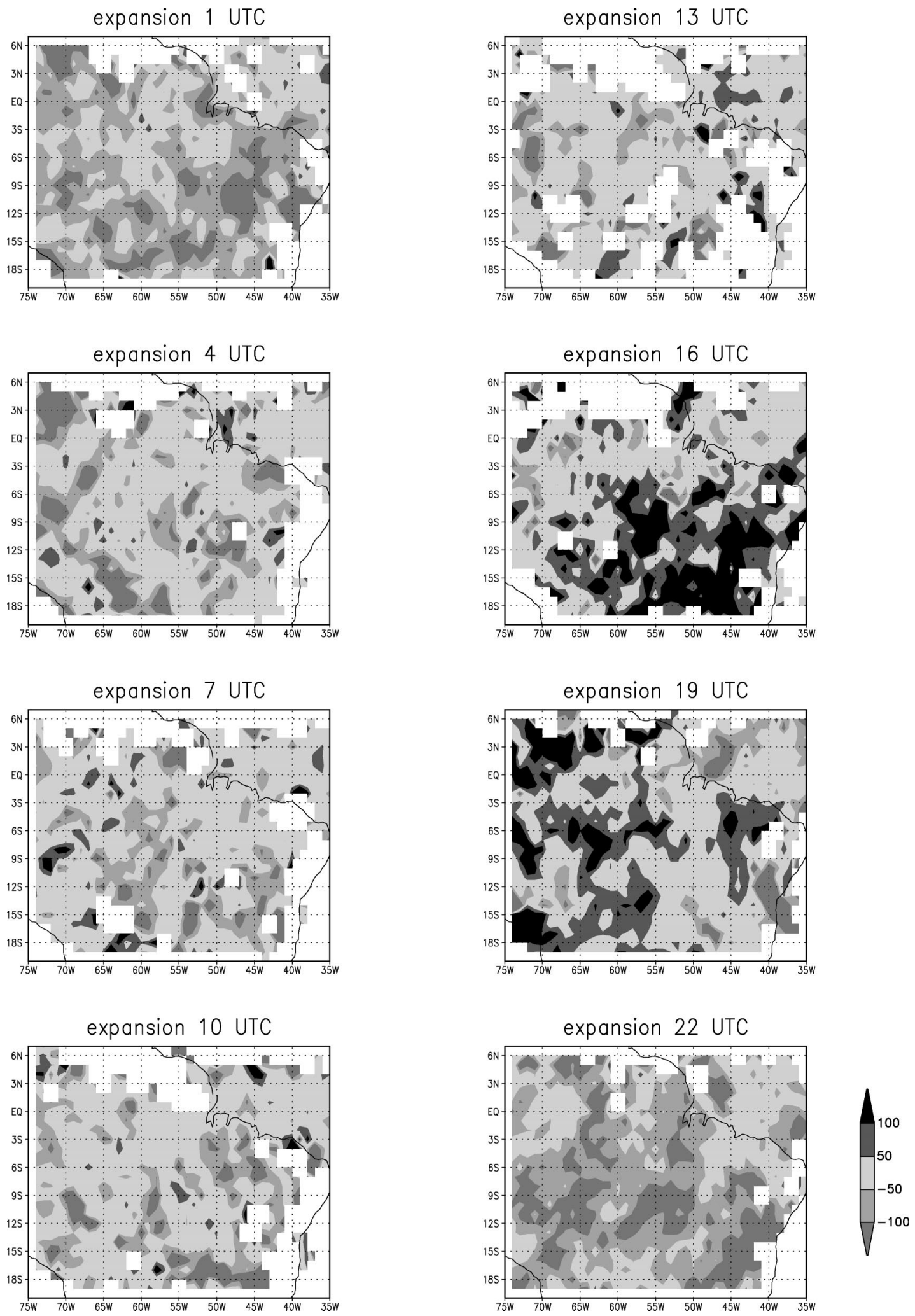

FIG. 8. Mean area expansion $\left(10^{-6} \mathrm{~s}^{-1}\right)$ over the period $10 \mathrm{Jan}-28$ Feb 1999 for different hours (UTC). 


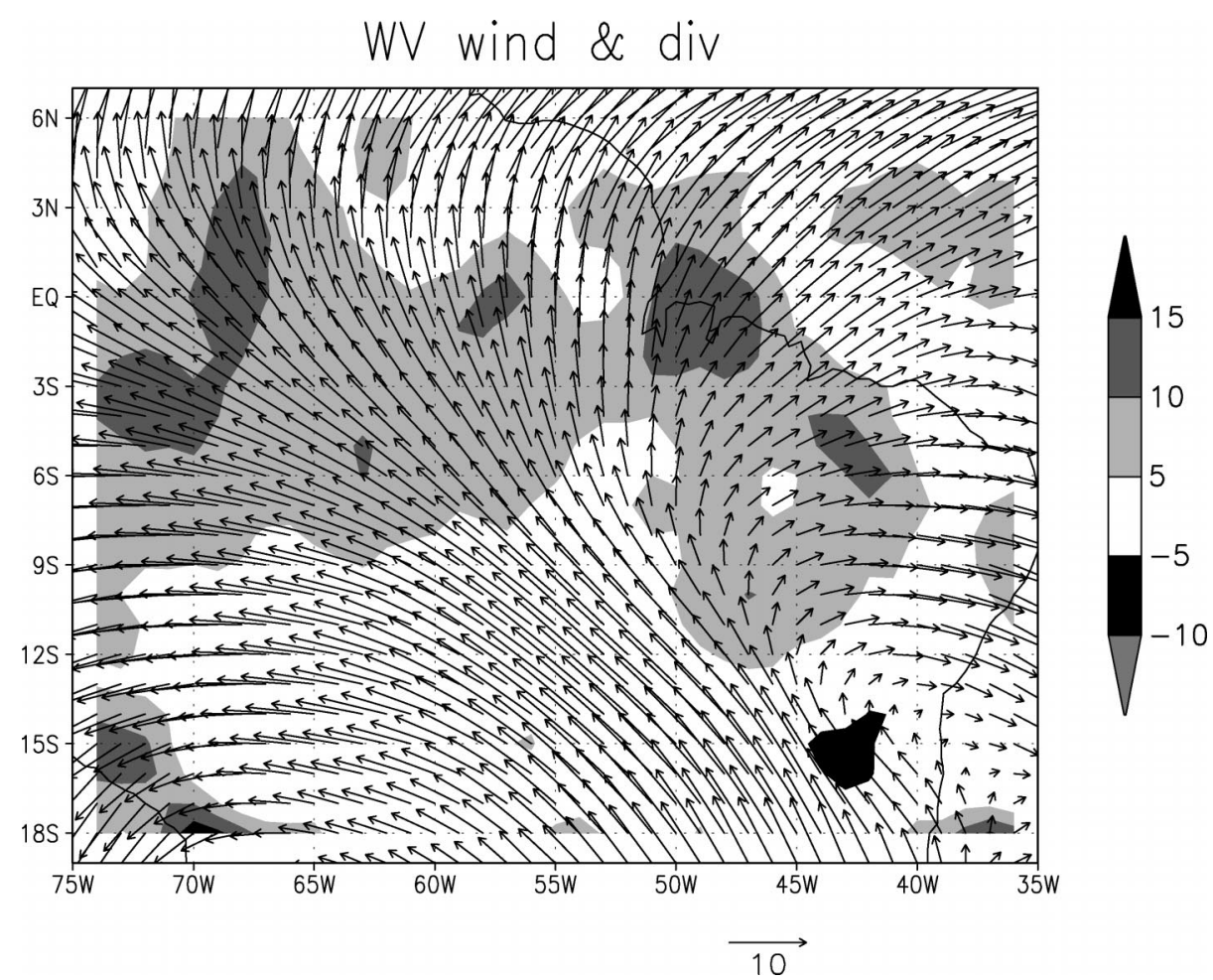

FIG. 9. Mean wind $\left(\mathrm{m} \mathrm{s}^{-1}\right)$ and wind divergence $\left(10^{-6} \mathrm{~s}^{-1}\right)$ over the period $10 \mathrm{Jan}-28$ Feb 1999 computed from the NOAA/NESDIS water vapor winds in the slice $150-250 \mathrm{hPa}$.

cloud fraction was very small during the night during the WETAMC/LBA period. Therefore the secondary maximum of divergence is probably not related to the convective systems, but rather to the large-scale field. There is a small time lag between the maxima: the area expansion peaks $1 \mathrm{~h}$ earlier than the wind divergence from radiosonde and $2 \mathrm{~h}$ earlier than the water vapor wind divergence; this feature will be discussed in the next section. It should also be noted that the number of
WV wind vectors in the level considered is drastically reduced during the morning because of the small cold cloud amount at that time. The values of the wind divergence are very different depending on the different calculations. This is probably due to the fact that the wind divergence is a parameter very sensitive to the spatial and time scales considered and to the different smoothness of the wind field from different sources. The WV winds are computed by tracking large-scale clouds

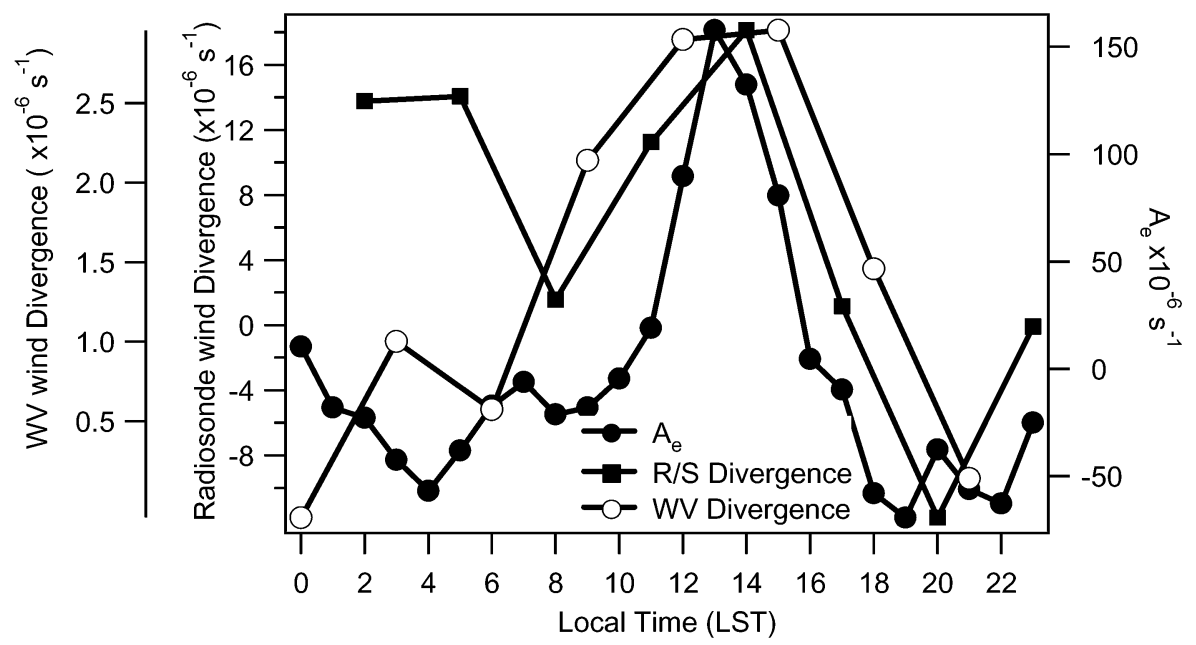

FIG. 10. Mean hourly area expansion, water vapor wind divergence, and radiosonde-derived wind divergence $\left(10^{-6} \mathrm{~s}^{-1}\right)$ for the $200-\mathrm{hPa}$ level in the WETAMC/LBA region. 


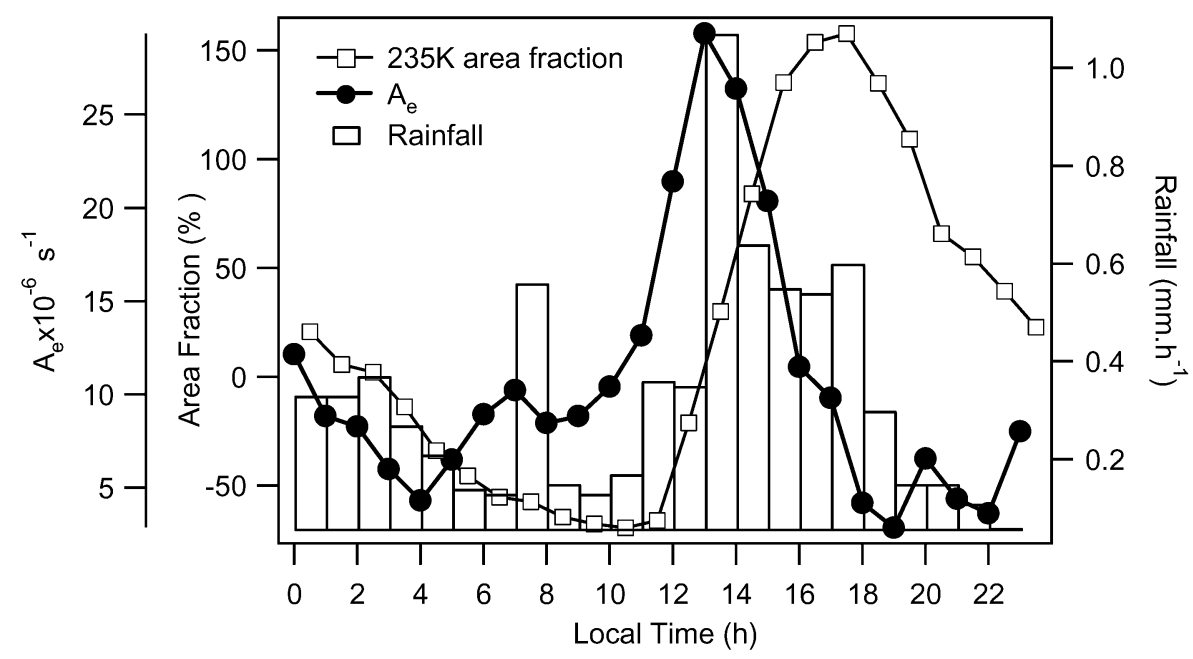

FIG. 11. Mean hourly area expansion $\left(10^{-6} \mathrm{~s}^{-1}\right)$, rainfall $\left(\mathrm{mm} \mathrm{h}^{-1}\right)$, and $235-\mathrm{K}$ area fraction $(\%)$ for the WETAMC/LBA region.

and water vapor structures using windows of about 130$\mathrm{km}$ width in three successive images, that is, over $1 \mathrm{~h}$. The flow of these structures is smoothed in comparison with the local wind as measured with radiosondes. Over the WETAMC/LBA area, the values of divergence calculated from the radiosondes are typically 4 times larger than those calculated from the WV winds and 8 times smaller than the area expansion. As already mentioned, the diurnal cycle of upper-level divergence is generally not observed elsewhere from the WV wind divergence, and the WV divergence signal observed over the WETAMC/LBA area is not significant according to the large standard deviation of this measurement. Radiosonde observations in other areas or other periods would be necessary to check the validity of the WV wind divergence diurnal cycle observed here.

Figure 11 shows the average diurnal cycle of the area expansion, rainfall, and $235-\mathrm{K}$ area fraction. It can be

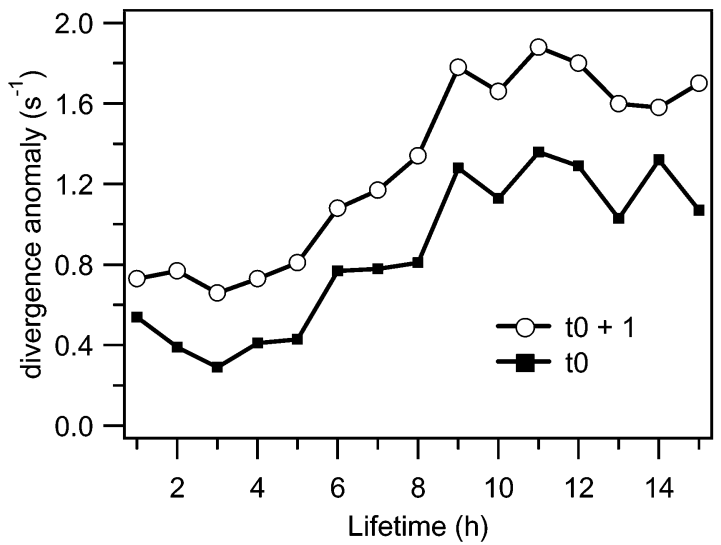

FIG. 12. Water vapor wind divergence anomaly $\left(10^{-6} \mathrm{~s}^{-1}\right)$ associated with the convective systems vs convective system lifetime (h) at the time of system initiation ( $\mathrm{t} 0$ ) or $1 \mathrm{~h}$ after the system initiation $(\mathrm{t} 0+1)$. seen that the maximum area expansion occurs close to the time of maximum precipitation and around $4 \mathrm{~h}$ before the maximum cold cloud fraction defined with the same threshold $(235 \mathrm{~K})$. This means that, for this region, the area expansion captures the moment of maximum precipitation, whereas a traditional approach to estimate the rainfall using brightness temperature would be biased by about $4 \mathrm{~h}$. As discussed by Machado et al. (2002), precipitation occurs very rapidly in the beginning of the afternoon close to the time of minimum total cloud cover. It is also the time when high and convective clouds have the maximum area fraction increase rate and when the initiation of convective systems and rain cells are the most numerous. These are the characteristics of the convection in the WETAMC/LBA region. However, other investigations are needed to determine whether the nearly simultaneous time of maximum precipitation, wind divergence, and area expansion could be verified in others regions of Amazonia.

\section{Area expansion and high-level wind divergence}

The relationships between convective system area expansion and high-level wind divergence have been further investigated by analyzing how the divergence varies over the convective system life cycle.

Figure 12 shows the high-level wind divergence anomaly observed over convective systems as a function of the lifetime of the systems. In order to remove the large-scale variation of the mean field (see Fig. 9), the divergence anomaly was computed in each grid point as the WV wind divergence minus the local mean. Then for each occurrence of a convective system, the divergence anomaly was considered at the system initiation time $(\mathrm{t} 0)$ or at a time lag $(\mathrm{t} 0+1 \mathrm{~h})$. The divergence anomaly is weak but always positive, and it increases with the system duration. The variability is large (stan- 
dard deviation of about $2 \times 10^{-6} \mathrm{~s}^{-1}$ ) and the signal is weak, but the mean signal is consistent with the behavior obtained with the area expansion (Fig. 2). Also, the divergence is larger when considering a time lag after the system initiation, with an optimum lag of 1 or $2 \mathrm{~h}$. We should remember the convective system initiation is defined here as the time when the cloud-top area colder than $235 \mathrm{~K}$ is larger than $3500 \mathrm{~km}^{2}$. This leads to an initiation time shifted with respect to the very beginning of the convection. This time lag between convective system initiation and high-level wind divergence is not surprising. Frank (1978) found large-scale convergence precedes by several hours the formation of convective systems observed in the Global Atmospheric Research Program's Atlantic Tropical Experiment (GATE). Tollerud and Esbensen (1985) performed a composite analysis of the wind divergence vertical profile for the large convective systems occurring during GATE. They concluded that the maximum low-level convergence is observed during the initiation stage, and the maximum upper-level divergence occurs during the mature stage.

The scale dependence of divergence estimation is not sufficient to explain the observed inconsistencies between wind divergence and area expansion. The cloud growing due to condensation cannot be neglected, as the area expansion depends on it and not only on the divergence. The area expansion reaches its maximum value in the initiation stage, and the upper-level wind divergence reaches the maximum later, at or just before the mature stage. The rate of increase of the total liquid water of the convective system cannot be neglected during the initiation stage, when the maximum area expansion occurs, and therefore Eq. (1) is not sufficient to describe the convective system size change. Time changes of the convective system area is a function of wind divergence (div) and condensation-evaporation process (cond) as follows:

$$
\begin{aligned}
\frac{1}{A} \frac{\partial A(\operatorname{div}, \text { cond })}{\partial t}= & \left.\frac{1}{A} \frac{\partial A(\operatorname{div})}{\partial t}\right|_{\text {cond }=\text { cte }} \\
& +\left.\frac{1}{A} \frac{\partial A(\text { cond })}{\partial t}\right|_{\text {div }=\text { cte }}, \\
\left.\frac{1}{A} \frac{\partial A(\operatorname{div})}{\partial t}\right|_{\text {cond }=\text { cte }}= & \nabla \cdot \mathbf{V}
\end{aligned}
$$

where $A$ is the area of the convective system and cte is a constant. Combining Eqs. (2) and (3) gives

$$
\frac{1}{A} \frac{\partial A(\operatorname{div}, \text { cond })}{\partial t}=\boldsymbol{\nabla} \cdot \mathbf{V}+\left.\frac{1}{A} \frac{\partial A(\text { cond })}{\partial t}\right|_{\text {div }=\text { cte }} .
$$

The liquid water content of the convective system $\left(Q_{1}\right)$ can be described as

$$
\begin{aligned}
Q_{l} & =\rho_{l} A H \quad \text { and } \\
\frac{\partial Q_{l}}{\partial t} & =\rho_{l} A \frac{\partial H}{\partial t}+\rho_{l} H \frac{\partial A(\text { cond })}{\partial t} \approx \rho_{l} H \frac{\partial A(\text { cond })}{\partial t},
\end{aligned}
$$

where $\rho l$ is the liquid water density, and $H$ is the convective system height. The top of the convective system, detected using a cold threshold, is close to the tropopause, and therefore $H$ variations are relatively small and can be neglected. Combining Eqs. (5) and (6), we obtain

$$
\frac{1}{A} \frac{\partial A(\text { cond })}{\partial t}=\frac{1}{A H \rho_{l}} \frac{\partial Q_{l}}{\partial t}=\frac{1}{Q_{l}} \frac{\partial Q_{l}}{\partial t} .
$$

Combining Eqs. (4) and (7) gives

$$
\frac{1}{A} \frac{\partial A}{\partial t}=\nabla \cdot \mathbf{V}+\frac{1}{Q_{l}} \frac{\partial Q_{l}}{\partial t} .
$$

To characterize and understand the evolution of the terms in Eq. (8) during the life cycle of the convective system, we have applied the following methodology. The life cycle is divided into five classes: initiation (class 1); intermediary between initiation and maximum size (class 2); maximum size, the mature stage (class 3 ); intermediary between maximum size and dissipation (class 4); and dissipation (class 5). Only systems with a lifetime longer than $3.5 \mathrm{~h}$ are considered in order to simplify the classification, and the few systems that last longer than $10 \mathrm{~h}$ are discarded to reduce the possibility of multiple growing phases. Also, the convective systems associated with splits or merges are discarded. Based on this classification we have done a composite study for each life stage, for the area expansion and the water vapor wind divergence, for the whole of tropical South America. The results of these calculations show that the area expansion ranges from $2 \times 10^{-4}$ to $-2 \times$ $10^{-4} \mathrm{~s}^{-1}$, whereas the divergence anomaly varies between $7 \times 10^{-7}$ and $6 \times 10^{-6} \mathrm{~s}^{-1}$. As already mentioned, the divergence is strongly scale dependent, and it is not possible to compare the absolute values of $\mathrm{WV}$ wind divergence with the area expansion for a large range of convective sizes. As we are here interested in the relative variations during the convective system life cycle, we plot in Fig. 13 the relative variations of the area expansion and divergence, that is, each parameter is normalized using its mean and standard deviation obtained from the composite analysis. As shown in Fig. 13, the normalized area expansion decreases linearly during the convective system life cycle in agreement with the results of Machado et al. (1998). Hence the evolution of the convective system area can be parameterized by

$$
\frac{1}{A} \frac{\partial A}{\partial t}=a t+b
$$

which leads to 


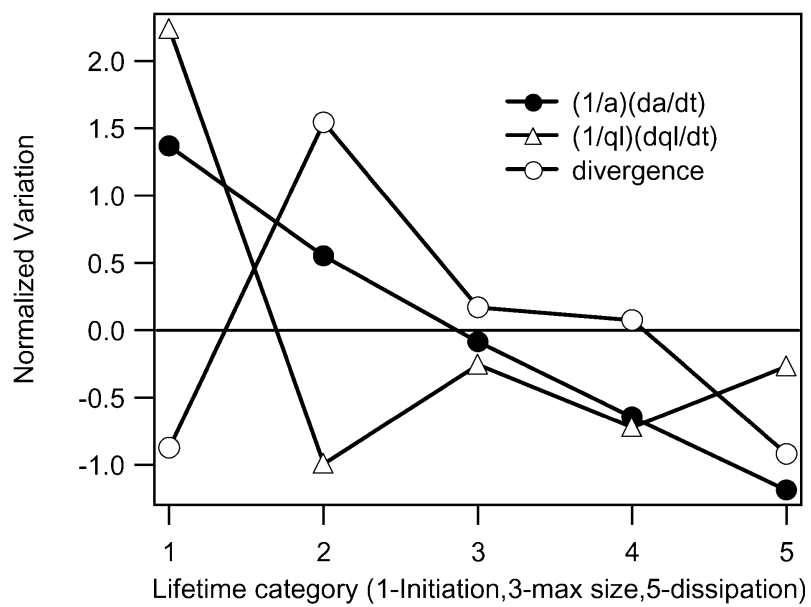

FIG. 13. Average variation of the normalized area fraction for convective systems having a duration between 3.5 and $10 \mathrm{~h}$, associated normalized anomalies of wind divergence, and calculated condensation/evaporation rate, as a function of the lifetime categories 1 (initiation), 2 (intermediary stage between initiation and mature stage), 3 [maximum area stage (mature stage)], 4 (intermediary stage between the mature and the dissipation stage), and 5 (dissipation stage). Values are normalized by their std dev.

$$
A=\exp \left(\frac{a t^{2}}{2}+b t+c\right),
$$

where $t$ is the time from the initiation.

The upper-level wind divergence is positive, on average, throughout the entire convective system life cycle. The normalized values show that the minimum is observed at the initiation time, and the maximum is reached during the growing phase of the system (class 2 in Fig. 13), close to the mature stage, and then decreases slowly in the dissipation phase.

Considering Eq. (8), the relative variation of the condensation term can be deduced from the difference between area expansion and horizontal wind divergence, using only the normalized terms. The following behavior can be seen in Fig. 13: at the initiation of the convective system the area expansion is very large, due mainly to a very strong condensation rate. Then the divergence increases during the growing phase. At the mature phase (maximum size), all terms are close to their mean value. During the dissipative phase, the negative area expansion is associated with both a small divergence and evaporation (Fig. 13 presents the relative variation). Based on this result the area expansion in the initiation stage is mainly due to the condensation rate and can provide important information for assimilation in mesoscale models to describe the vigor of the convection during the model spinup.

\section{Conclusions}

The WETAMC/LBA makes it possible to study convective systems and their associated precipitation from the combination of satellite images, meteorological radars and rain gauges, and radiosonde data for dynamic and thermodynamic analysis.

The full-resolution GOES-8 satellite images were used to detect and track the convective systems during their life cycle. This objective tracking was performed for 48 days during the WETAMC/LBA over a window covering tropical South America.

The convective system area is calculated from the number of pixels with a brightness temperature smaller than the threshold considered $(235$ or $210 \mathrm{~K})$. The area expansion is defined as the system area difference between two successive images, normalized by the mean area. The area expansion is closely linked to the phase of the convective system's life. At the beginning of its life, the convective system presents a large positive area expansion. The area expansion becomes close to zero during the mature stage of the convective system and negative in the dissipation stage.

The results demonstrate the ability to predict the probable lifetime of a convective system from its initial area expansion. The physical explanation for this result is founded on the principle that this parameter measures the vigor of the convective forcing indicating the timespace scale of the convective cloud organization. The area of the cloud shield of the convective system changes in association with the upper-level wind divergence and with the condensation/evaporation process. A rapidly growing convective system is a cloud cluster with strong liquid water condensation and strong vertical mass flux. The area increase in the initial stage is mainly due to the condensation process, then afterward, in the mature stage, the upper-air wind divergence increases. The upper-air divergence is a signature of the mass flux inside the convective towers that had previously contributed to the condensation process. The average area expansion at the initial stage varies exponentially with the life cycle duration. For short to medium lifetimes (less than $8 \mathrm{~h}$ ) the relationship between initial area expansion and total lifetime is very clear; however, for longer lifetimes all that can be predicted is that the convective system will live for longer than $8 \mathrm{~h}$. Very long lifetimes cannot be predicted from the signature of the vigor of the convection at the initial stage, probably because of the diurnal cycle, the large-scale forcing, and other external forcing. This time scale of $8 \mathrm{~h}$ applies to the cloud shield defined at $235 \mathrm{~K}$. For the colder cloud area of $210 \mathrm{~K}$ this time scale is around 5-6 h and for the liquid water at $2 \mathrm{~km}$ (using the CAPPI 2-km radar data) this time scale is only of a couple of hours.

The maximum area expansion occurs close to the time of maximum precipitation and about $4 \mathrm{~h}$ before the maximum cold cloud fraction at the same threshold (235 $\mathrm{K})$. It can be concluded that the area expansion could be used to determine the time of maximum precipitation.

The analysis of the area expansion showed that this parameter could be very useful for short-range forecasts, convection diagnostics, and perhaps to help improve the 
precipitation estimation from geostationary meteorological satellites. Also, the area expansion can be used to determine the convective system life stage and to supply information about the condensation processes and the upper-level divergence.

Future work might include seeing if the parameterized relationship in equation 10 has predictive value anywhere else, particularly the midlatitudes.

Acknowledgments. This study was done in a cooperative framework between the $\mathrm{CNPq}$ (Conselho Nacional de Desenvolvimento Cientifico e Tecnólogico, Brazil) and the IRD (Institut de Recherche pour le Développement, France), support number 690089/01-5. The work has received financial support from the $\mathrm{CNPq}$ Grant 47210/2001-4.

\section{REFERENCES}

Anagnostou, E. N., and W. F. Krajewski, 1997: Simulation of radar reflectivity fields: Algorithm formulation and evaluation. Water Resour. Res., 33, 1419-1428.

—_ and C. A. Morales, 2002: Rainfall estimation from TOGA radar observations during LBA field campaign. J. Geophys. Res., 107, 8068, doi:10.1029/2001JD000377.

Barnes, S. L., 1964: A technique for maximizing details in numerical weather map analysis. J. Appl. Meteor., 3, 396-409.

Frank, W. M., 1978: The life cycles of GATE convective systems. $J$. Atmos. Sci., 35, 1256-1264.

Holton, J. R., 1979: An Introduction to Dynamic Meteorology. Academic Press, $394 \mathrm{pp}$.

Laurent, H., 1993: Wind extraction from METEOSAT water vapor channel image data. J. Appl. Meteor., 32, 1124-1133.

- and M. Sakamoto, 1998: Measure of divergence at the top of tropical convective systems from water vapor winds. Proc.
Fourth Int. Winds Workshop, Saanenmoser, Switzerland, EUMETSAT, 155-161.

- , L. A. T. Machado, C. A. Morales, and L. Durieux, 2002: Characteristics of the Amazonian mesoscale convective systems observed from satellite and radar during the WETAMC/ LBA experiment. J. Geophys. Res., 107, 8054, doi:10.1029/ 2001JD000337.

Machado, L. A. T., 2000: The Amazon energy budget using the ABLE-2B and FluAmazon data. J. Atmos. Sci., 57, 3131-3144. , W. B. Rossow, R. L. Guedes, and A. W. Walker, 1998: Life cycle variations of mesoscale convective systems over the Americas. Mon. Wea. Rev., 126, 1630-1654.

- , H. Laurent, and A. A. Lima, 2002: Diurnal march of the convection observed during TRMM-WETAMC/LBA. J. Geophys. Res., 107, 8064, doi:10.1029/2001JD000338.

Mathon, V., and H. Laurent, 2001: Life cycle of the Sahelian mesoscale convective cloud systems. Quart. J. Roy. Meteor. Soc., 127, 377-406.

Petersen, W. A., S. W. Nesbitt, R. J. Blakeslee, R. Cifelli, P. Hein, and S. A. Rutledge, 2002: TRMM observations of intraseasonal variability in convective regimes over the Amazon. J. Climate, 15, 1278-1294.

Schmetz, J., and Coauthors, 1995: Monthly mean large-scale analyses of upper-tropospheric humidity and wind field divergence derived from three geostationary satellites. Bull. Amer. Meteor. Soc., 76, 1578-1584.

Scofield, R. A., 1987: The NESDIS operational convective precipitation estimation technique. Mon. Wea. Rev., 115, 1773-1792.

Silva Dias, M. A., and Coauthors, 2002: Cloud and rain processes in a biosphere-atmosphere interaction context in the Amazon region. $J$. Geophys. Res., 107, 8072, doi:10.1029/2001JD000335.

Tollerud, E. I., and S. K. Esbensen, 1985: A composite life cycle of nonsquall mesoscale convective systems over the tropical ocean. Part I: Kinematic fields. J. Atmos. Sci., 42, 823-837.

Velden, C., C. M. Hayden, S. J. Nieman, W. P. Menzel, S. Wanzong, and J. S. Goerss, 1997: Upper-tropospheric winds derived from geostationary satellite water vapor observations. Bull. Amer. Meteor. Soc., 78, 173-195.

Wallace, J. M., and P. V. Hobbs, 1979: Atmospheric Science: An Introductory Survey. Academic Press, $467 \mathrm{pp}$. 